\title{
DETERMining THE STRENGTH OF COMPOSITE INTEGRATED JOINTS USING NUMERICAL SIMULATIONS
}

\author{
Frantisek Sedlacek, Vaclava Lasova
}
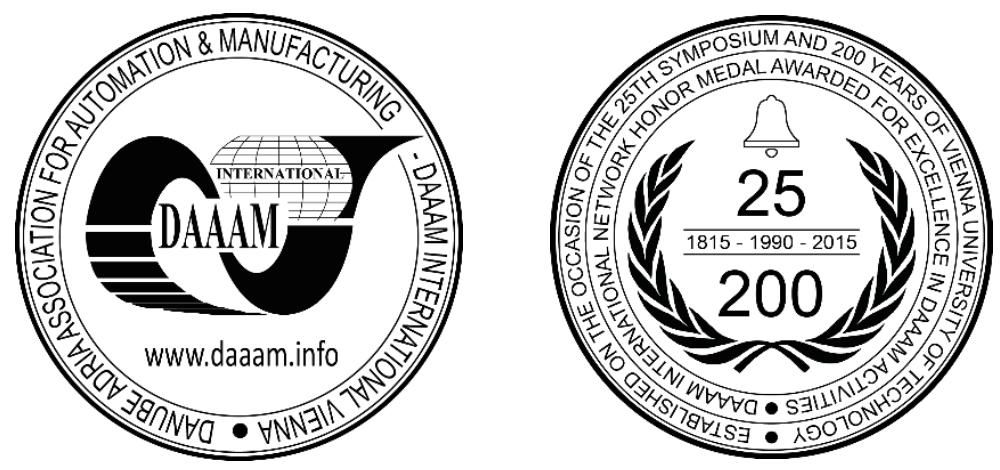

This Publication has to be referred as: Sedlacek, F[rantisek] \& Lasova, V[aclava] (2017). Determining the Strength of Composite Integrated Joints Using Numerical Simulations, Proceedings of the 28th DAAAM International Symposium, pp.0545-0554, B. Katalinic (Ed.), Published by DAAAM International, ISBN 978-3-902734-11-2, ISSN 1726-9679, Vienna, Austria

DOI: $10.2507 / 28$ th.daaam.proceedings.077

\begin{abstract}
The paper deals with determining the strength of integrated high performance composite joints using numerical simulations. The solution of integrated joints made from composite materials is very problematic because it involves multi-axial stress. Wrapping loops were chosen as simplified specimens for validation of the numerical simulations and experimental tests. The wrapping loops were fabricated from unidirectional E-Glass roving in combination with an epoxy matrix. The experimental tensile tests were carried out on a Zwick/Roell Z050 machine. A ply-based FEM model was used for structural analysis. Four failure criteria for composite materials were used to determine the strength of the loops. There were favourable comparisons between the numerical simulations and the experimental tests, especially when using the Tsai-Wu failure criterion.
\end{abstract}

Keywords: Composite materials; Integrated High Performance Joints; numerical simulation; FEM

\section{Introduction}

Industrial development is becoming more and more rapid, thus increasing the demands on the products themselves. Especially in fields such as aerospace, automotive, railway, yachting or motorsports there are high requirements for low weight, high fatigue life, damping and vibro-acoustic properties of the materials. This is why using composite materials is advantageous. These materials are increasingly used today. Significant advances in virtual prototyping, which allow design and optimization of the complex composite parts using advanced numerical simulations is one reason for the growth in the use of composite materials.

The joints in composite parts are one of the most difficult areas when designing highly-stressed components. The joining of composite materials with composite materials or metals can be divided into five main groups: connections using additional materials (adhesive bonded joints or welded joints), friction joints (pressed joints), connections with an auxiliary element (bolted joints or riveted joints), joints that use the shape of the connected parts, and integrated high performance joints (IHPJ). The last group is preferred for composite materials, because this type of connection allows easy disassembly of the components and the reinforcement fibres are not disturbed by machining. 
But this type of connection has many complications associated with it during the design phase and subsequently there are technological problems in fabrication. Determination of the strength of an IHPJ is most problematic because there is multi-axial stress across the whole joint. Much research has been done dealing with this issue [1], [2]. This paper deals with the determination of the strength of an integrated high performance joint using numerical simulation and a ply-based finite element model. Four three-dimensional failure criteria for composite materials were used to determine the strength of the joints.

\section{Failure criteria for composite materials}

Failure criteria for composite materials are still in the beginning against isotropic materials, whose has margin in an attempt to describe their violation more than two centuries (such as Coulomb, Mohr, etc. [3], [4]). Predicting the failure of these materials is very complex. Failure is influenced by many factors (such as type of load, layout of the plies of the laminate, the type of the constituents of the composite (fibres and matrix), their volume fraction, etc. The failure criteria for composite materials are based on the failure criteria for homogenous (isotropic) materials.

Most of these criteria assume that the material is homogenous (is not differentiated between fibres and matrix) and the stress is linear until failure occurs. There are several macro-mechanical failure criteria for composite materials (with transverse-isotropic or orthotropic properties).

In general, these failure criteria can be divided into three main groups: non-interactive failure criteria, interactive failure criteria and direct-mode failure criteria. The non-interactive theories do not consider the interaction between different stress components (normal and shear stresses in the main directions), whereas the interactive theories do [5]. The direct-mode criteria uses so-called failure modes which are described by independent conditions.

In this paper, four failure criteria for determining the strength of the wrapped loops are used. One non-interactive failure criterion - maximum stress, and three interactive failure criteria - Hoffman, Hill and Tsai-Wu, are used.

\subsection{Maximum stress failure criterion}

This failure criterion is one of the most frequently used theories for predicting the strength of composite materials. This criterion was first used by C. F. Jenkins in 1920 [6], and was created based on W. J. M. Rankin's theory Maximum normal stresses for isotropic materials [7]. According to this theory, failure occurs if any stress component has reached the ultimate strength of the material [8], [9]. Failure indexes for individual directions of this strength criterion are listed in equation (1).

\begin{tabular}{lcc} 
Failure & Maximum stress criterion \\
\hline$F_{11}$ & $\sigma_{1} / X^{T}$ & if $\sigma_{1}>0 ; \sigma_{1} / X^{C}$ if $\sigma_{1}<0$ \\
$F_{22}$ & $\sigma_{2} / Y^{T}$ if $\sigma_{2}>0 ; \sigma_{2} / Y^{C}$ if $\sigma_{2}<0$ \\
$F_{33}$ & $\sigma_{3} / Z^{T}$ if $\sigma_{3}>0 ; \sigma_{3} / Z^{C}$ if $\sigma_{3}<0$ \\
$F_{12}$ & $\left|\tau_{12} / S_{12}\right|$ \\
$F_{23}$ & $\left|\tau_{23} / S_{23}\right|$ \\
$F_{13}$ & $\left|\tau_{13} / S_{13}\right|$ \\
\hline
\end{tabular}

where $\sigma_{1}\left(\sigma_{2}, \sigma_{3}\right)$ is normal stress in the longitudinal (transverse) direction; $\mathrm{X}^{\mathrm{T}}\left(\mathrm{Y}^{\mathrm{T}}, \mathrm{Z}^{\mathrm{T}}\right)$ is tensile strength in the longitudinal (transverse) direction; $\mathrm{X}^{\mathrm{C}}\left(\mathrm{Y}^{\mathrm{C}}, \mathrm{Z}^{\mathrm{C}}\right)$ is compressive strength in the longitudinal (transverse) direction; $\tau_{12}\left(\tau_{23}\right.$, $\left.\tau_{13}\right)$ is shear stress in plane 12 (23 or 13) and $S_{12}\left(S_{23}, S_{13}\right)$ is shear strength in plane 12 (23 or 13) [10].

\subsection{Hill failure criterion}

The Hill failure criterion is based on the von Mises theory for isotropic materials. Hill extended this condition for orthotropic materials. This failure criterion assumes the same tensile and compressive strengths of the material $\left(X^{T}=X^{C}\right)$ [11]. Assuming the plane stress (ie . $\sigma_{33}=\sigma_{13}=\sigma_{23}=0$ ), Hill's failure criterion can be written in the form:

$$
\left(\frac{\sigma_{1}}{X^{T}}\right)^{2}+\left(\frac{\sigma_{2}}{Y^{T}}\right)^{2}-\left(\frac{1}{\left(X^{T}\right)^{2}}+\frac{1}{\left(Y^{T}\right)^{2}}-\frac{1}{\left(Z^{T}\right)^{2}}\right) \sigma_{1} \sigma_{2}+\left(\frac{\sigma_{12}}{S^{T}}\right)^{2}=1
$$




\subsection{Hoffman failure criterion}

Hoffman modified Hill's strength criterion for different tensile and compressive strengths [12]. Hoffman's failure criterion can be written (for plane stress) in the form:

$$
\frac{\sigma_{1}{ }^{2}}{X^{T} X^{C}}+\frac{\sigma_{2}{ }^{2}}{Y^{T} Y^{C}}-\frac{\sigma_{1} \sigma_{2}}{X^{T} X^{C}}+\frac{X^{C}-X^{T}}{X^{T} X^{C}} \sigma_{1}+\frac{Y^{C}-Y^{T}}{Y^{T} Y^{C}} \sigma_{2}+\frac{\sigma_{12}^{2}}{\left(S^{L}\right)^{2}}=1 .
$$

\subsection{Tsai-Wu failure criterion}

The first attempt to develop a general theory of damage of anisotropic materials was made by Gol'denblat and Kopnov [13]. Their theory was an effort to predict the failure of a material under a general state of stress. The concept of a tensor strength is introduced, which takes into account the transformation from one coordinate system to another. It has the form of an invariant (formed by the stress and deformation tensor components), and it is able to explain the difference between the tensile and compressive strength. Based on this, Tsai and Wu created a failure criterion in the form of the polynomial

$$
f_{i} \sigma_{i}+f_{i j} \sigma_{i} \sigma_{j}=1 ; \quad i, j=1,2, \ldots, 6
$$

Where $f_{i}$ and $f_{i j}$ are tensors of the first and second order of the strength, which can only be determined using experimental tests [14], [15]. For the plane stress condition, the Tsai-Wu failure criterion can be written in the form

$$
\left(\frac{1}{X^{T}}-\frac{1}{X^{C}}\right) \sigma_{1}+\left(\frac{1}{Y^{T}}-\frac{1}{Y^{C}}\right) \sigma_{2}+\frac{\sigma_{1}^{2}}{X^{T} X^{C}}+\frac{\sigma_{2}^{2}}{Y^{T} Y^{C}}+\frac{\sigma_{12}^{2}}{\left(S^{L}\right)^{2}}+2 F_{12}^{*} \frac{\sigma_{1} \sigma_{2}}{X^{T} X^{C}}=1,
$$

where the coefficient of the interaction $F_{12}^{*}$ can be written as

$$
F_{12}^{*}=\frac{1}{2 \sigma^{2}}\left\{1-\left[X^{C}-X^{T}+\frac{X^{T} X^{C}}{Y^{T} Y^{C}}\left(Y^{C}-Y^{T}\right)\right] \sigma+\left(1+\frac{X^{T} X^{C}}{Y^{T} Y^{C}}\right) \sigma^{2}\right\}
$$

where $\sigma$ is the stress at which failure occurs during a biaxial experimental test. The interaction coefficient $F_{12}^{*}$ cannot be determined without this experimental test. Several papers deal with this coefficient, and most of them consider that the value of this coefficient is usually equal to zero [12], [16], meaning that $F_{12}^{*}=0$ provides more than enough accuracy for engineering applications.

\section{Samples for experimental measurements}

The simplified samples in the shape of loops were created to validate the numerical simulations. The loops were fabricated in a special mould. The wrapped loops were made from unidirectional E-glass roving (Aeroglass TEX 2400) and high-strength epoxy matrix LH289. The mechanical properties of the laminate are given in

Table 1. A total of sixteen samples in two geometrical variants were created (with four threads and seven threads of glass roving). The geometry of the specimen is shown in Fig. 1. The geometrical parameters of the samples (wrapping loops). Fig. 1.

\begin{tabular}{lccl}
\hline$V_{f}$ & $(-)$ & 0.60 & Volume fraction of the fibres \\
$V_{m}$ & $(-)$ & 0.40 & Volume fraction of the matrix \\
$E_{1}$ & $(\mathrm{MPa})$ & 46400 & Young's module in direction 11 \\
$E_{2}$ & $(\mathrm{MPa})$ & 12700 & Young's module in direction 22 \\
$G_{12}$ & $(\mathrm{MPa})$ & 3490 & Shear module of elasticity in direction 12 \\
$G_{23}$ & $(\mathrm{MPa})$ & 3770 & Shear module of elasticity in direction 23 \\
$G_{13}$ & $(\mathrm{MPa})$ & 3460 & Shear module of elasticity in direction 13 \\
$v_{12}$ & $(-)$ & 0.262 & Poisson's ratio in plane 12 \\
$v_{23}$ & $(-)$ & 0.350 & Poisson's ratio in plane 23 \\
$X^{T}$ & $(\mathrm{MPa})$ & 1240 & Ultimate tensile stress in direction 11 \\
$X^{C}$ & $(\mathrm{MPa})$ & 774 & Ultimate compressive stress in direction 11 \\
$Y^{T}$ & $(\mathrm{MPa})$ & 43.9 & Ultimate tensile stress in direction 22 \\
$Y^{C}$ & $(\mathrm{MPa})$ & 82 & Ultimate compressive stress in direction 22 \\
$S_{12}$ & $(\mathrm{MPa})$ & 55.8 & Ultimate shear stress in direction 12 \\
\hline
\end{tabular}


Table 1. Mechanical properties of the composite material of the samples.
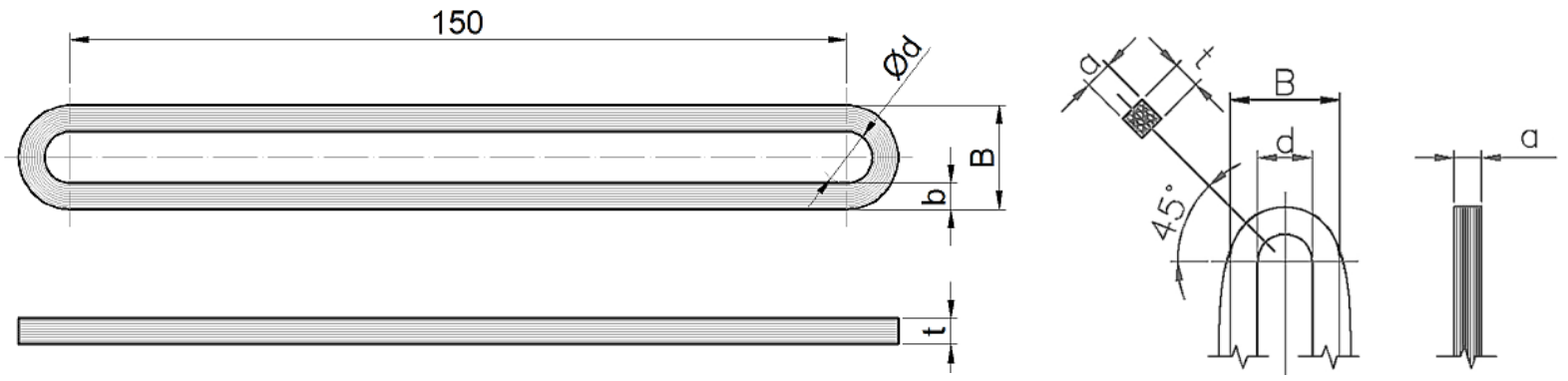

Fig. 1. The geometrical parameters of the samples (wrapping loops).

\section{Experimental measurement of the samples}

The experimental tensile tests of the loops were carried out using a quasi-static load $(0.5 \mathrm{~mm} / \mathrm{sec})$ in a Zwick/Roell machine (Z050). The specimens were attached using pins in special jaws (without axial contact). The process of the failure of the loops was recorded using a DSLR camera (with full synchronization with the experimental output data) see Fig. 2.
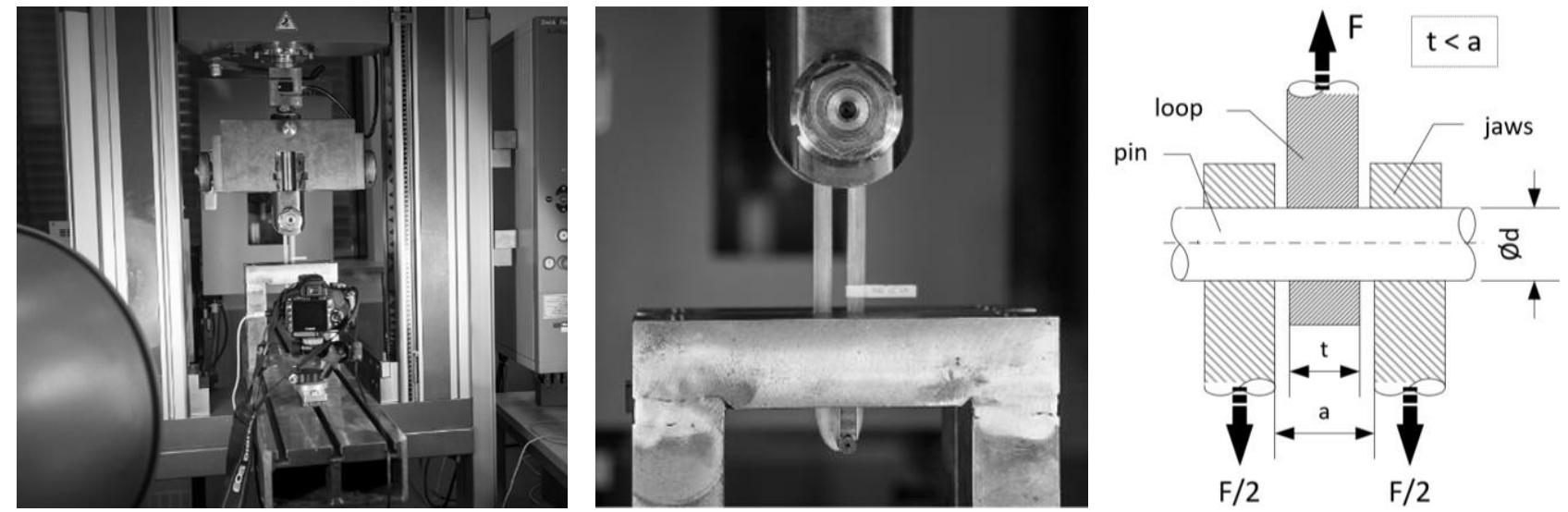

Fig. 2. Experimental tensile test of the specimen: (left) tensile test, (centre) detail of the attachment of the specimen, (right) diagram of the attachment of the specimen.

The test specimens were broken during the tensile tests in the following order: first, the matrix of the laminate in the contact cylindrical face of the loop was damaged. After reaching the maximum load the first (inner) thread of the fibre was broken.

Subsequently the remaining fibres were broken (fibre after fibre from inner to outer diameter until full failure of the loop). The loops were most often broken in the contact cylindrical face approximately at an angle $45^{\circ} \pm 10^{\circ}$ relative to the longitudinal plane of the loop. The progression of the failure of the loop is shown in Fig. 3.
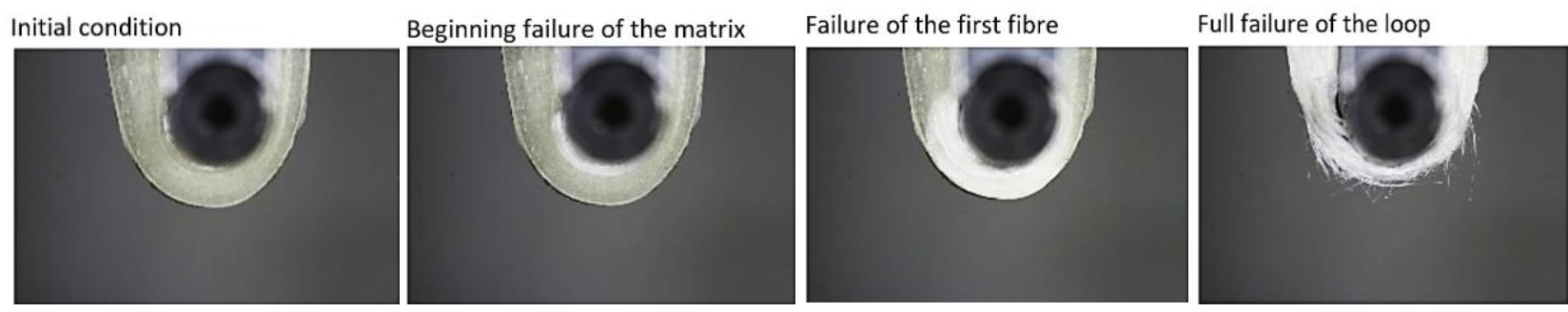

Fig. 3. Progression of the failure of the loop with seven threads of fibres.

The results of the tensile tests of the loops with four and seven threads of fibres are given in Fig. 4. Where the failure of the loops with four threads of fibres occurred on average around $5008 \mathrm{~N}$, and for seven threads of fibres occurred on average around $5480 \mathrm{~N}$. 


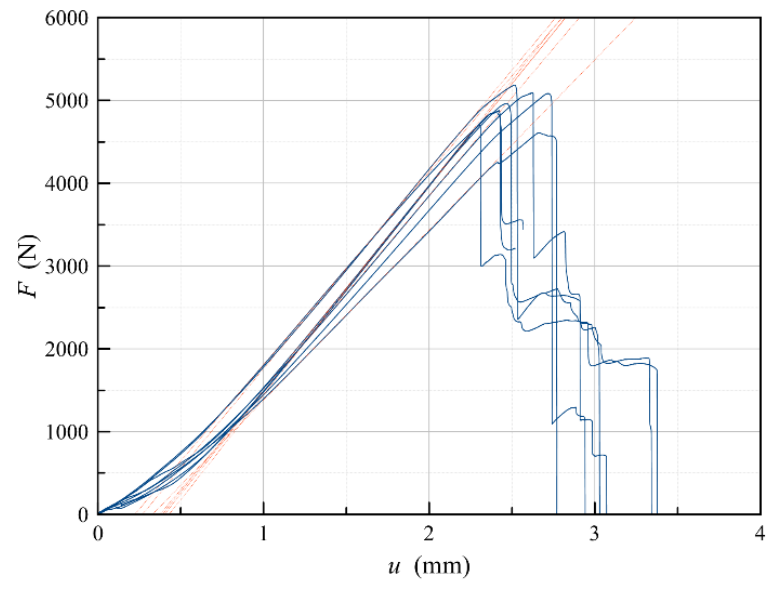

(a) Four threads of fibres

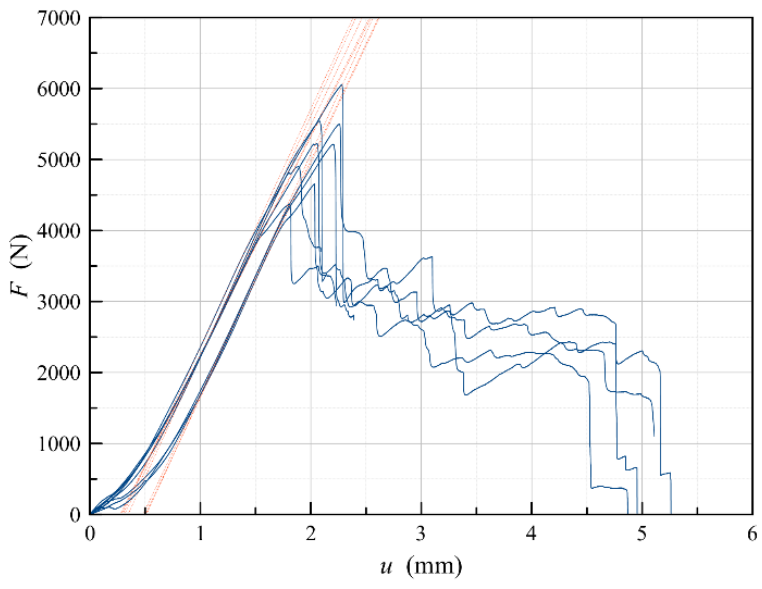

(b) Seven threads of fibres

Fig. 4. Results of the tensile tests of the loops (specimens).

\section{Numerical simulation of the wrapping loops}

\subsection{FEM model of the wrapping loop}

The numerical simulation was done using the NX Nastran 11 solver (based on FEM) and the Siemens Simcenter 11 pre/post-processor. The ply-zone process of meshing was used for this solution. A 2D mesh with CQUAD8 isoparametric hexahedron elements was applied on the model of the loop. The layout of the individual plies and the physical properties were defined.

Subsequently, this 2D mesh was extruded into a full three-dimensional FEM model (with CHEXA20 elements). The 3D mesh respects the layers, the thicknesses and the material orientation of the individual plies of the laminate (see Fig. 5). The possibility of determining the stress, strain and failure in individual planes (bottom/middle and top) of the plies is the main advantage of this type of meshing.

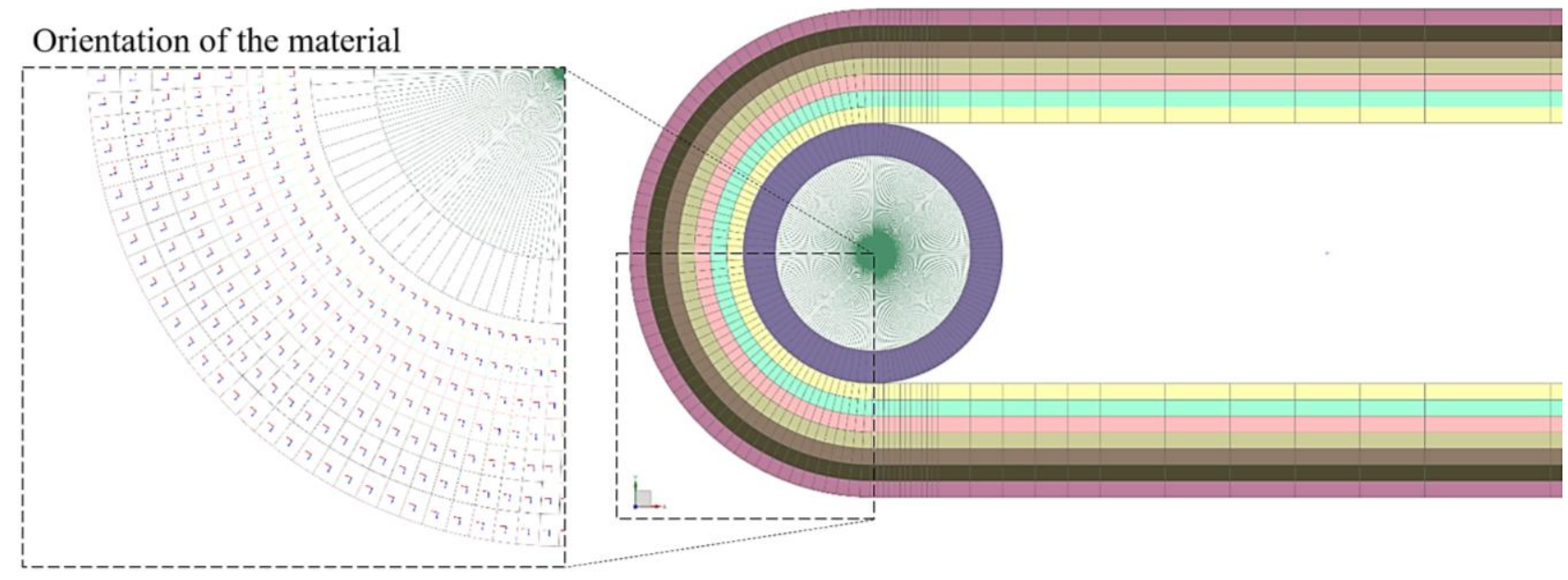

Fig. 5. FEM mesh of the wrapping loop with seven threads of fibres.

\subsection{Results of the simulation}

The structural analysis was done using the non-linear solver NX Nastran 401 and the NX Laminate Composite module. Four failure criteria were used: Maximum stress, Hill's, Hoffman's and Tsai-Wu failure criterion (see section 2). The joint was solved until failure index $F_{I}=1$ was reached.

The results of the main normal stress of the loop (for average critical loading of the specimens during the experimental tests $F_{F F 4 \_A V G}=5008 \mathrm{~N}$ ) are shown in

Fig. 6. 

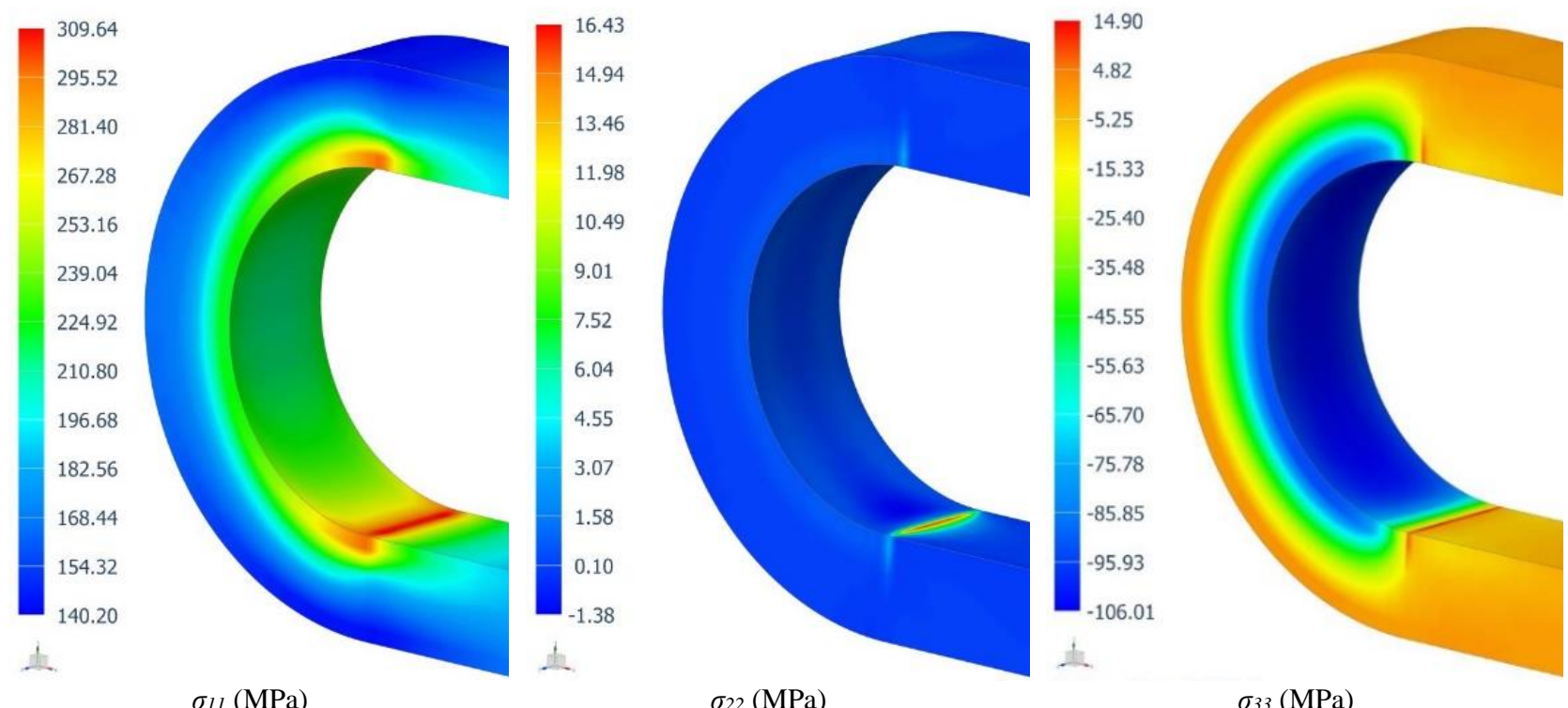

$\sigma_{22}(\mathrm{MPa})$

$\sigma_{33}(\mathrm{MPa})$

Fig. 6. The main normal stress of the loop with four threads of fibres.

The results of the failure criteria were compared with the experimental tensile tests of the specimens. The results of the bottom plane of the first ply of the wrapping loop (the inner contact face of the loop) were compared with the results from the beginning of the failure of the loop (failure matrix).

The results in the middle plane of the first ply of the loop were compared with the maximum loading condition from the experimental tests (= failure of the first fibre).

The results of the maximum stress failure criterion are given in Fig. 7. A third failure index $F_{33}$ was determined as critical. This means that the most critical stress is in the third main normal direction of the laminate (radial stress). The critical area of the failure was found at the contact cylindrical face of the loop approximately at an angle $60^{\circ} \pm 10^{\circ}$ relative to the longitudinal plane of the loop.

Compliance with a deviation up to $10 \%$ was determined in comparison with the experimental tests results (up to $7 \%$ for beginning of failure and up to $10 \%$ for full failure of the loop).

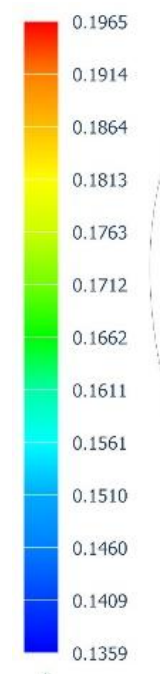

the

Units $=$ Unitless

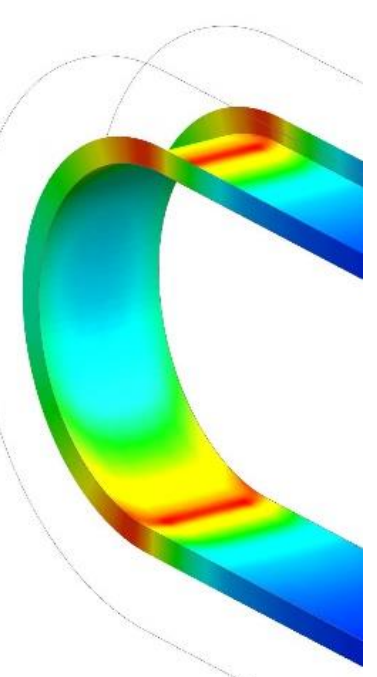

$F_{11}(-)$

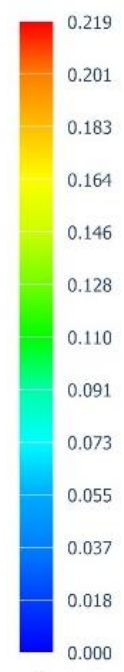

Units = Unitless

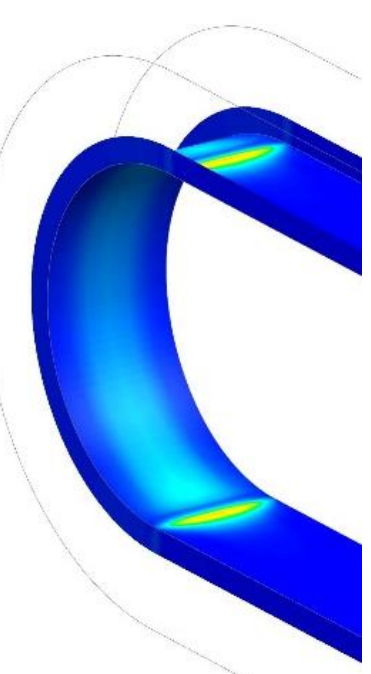

s.

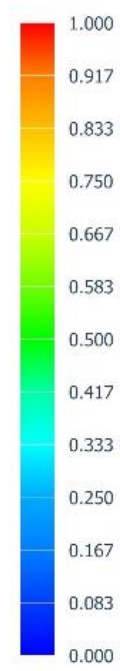

$\frac{1}{\text { Units }}$

Units $=$ Unitless

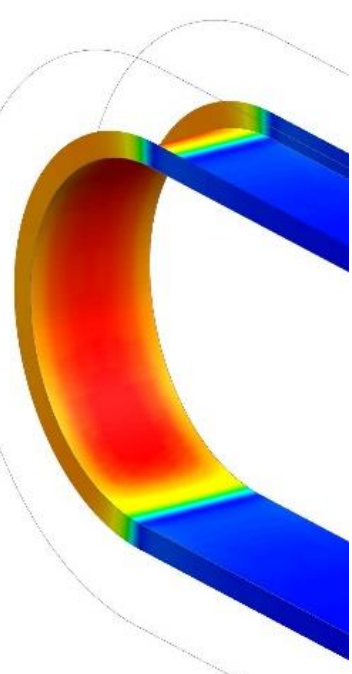

$F_{33}(-)$ 

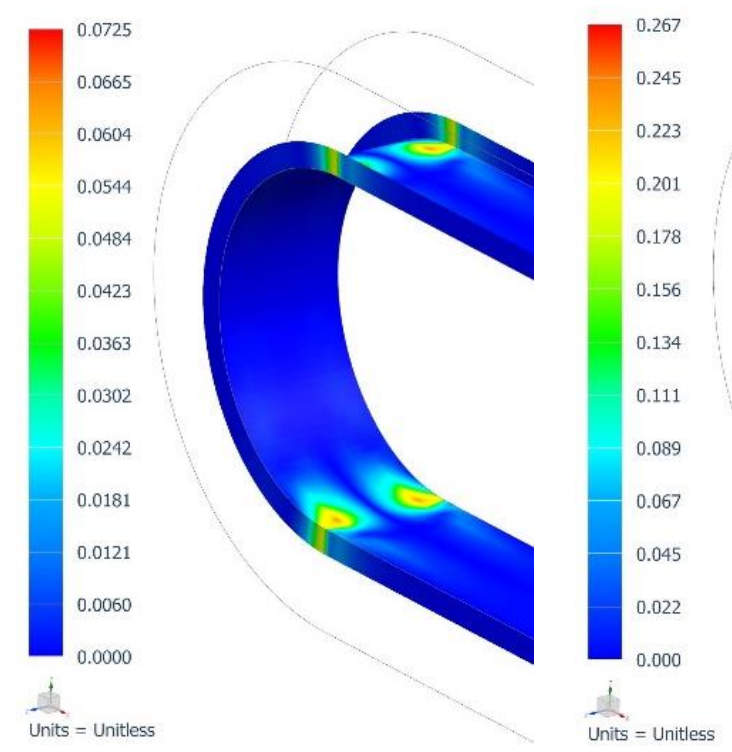

$F_{12}(-)$

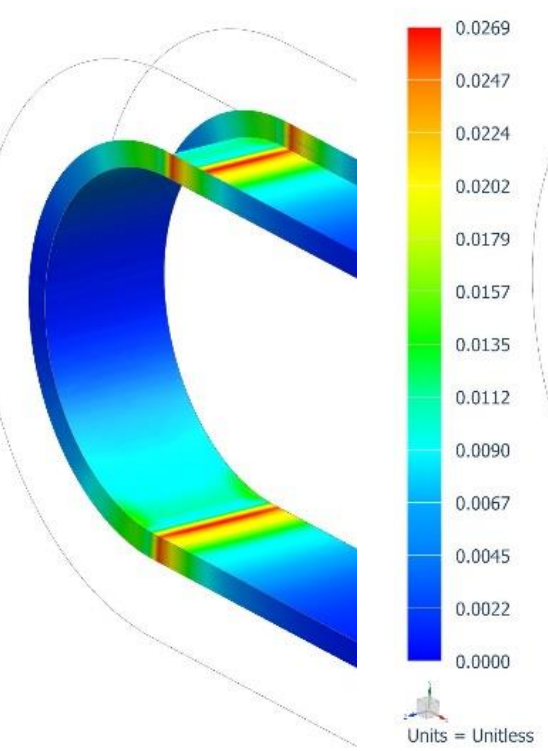

$F_{23}(-)$

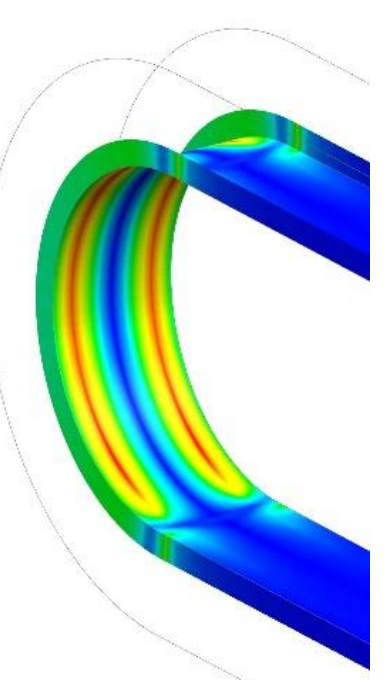

$F_{31}(-)$

Fig. 7. Results of maximum stress failure criterion in middle plane of first (critical) ply of loop with four threads of fibres.

The results of Hill's failure criterion are given in Fig. 8. This failure criterion has only one failure index. The critical area of the failure was found on the contact cylindrical face of the loop at an angle between $15^{\circ}$ to $70^{\circ}$ relative to the longitudinal plane of the loop. Compliance with deviation up to $8 \%$ was determined in comparison with the experimental tests results (up to $4 \%$ for beginning of failure and up to $8 \%$ for full failure of the loop).

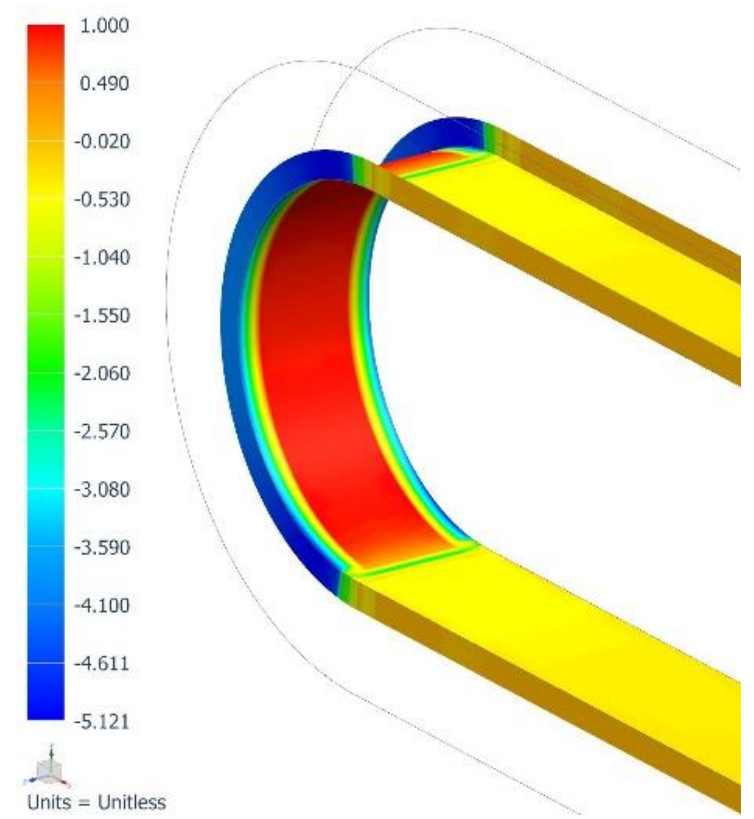

First ply - Bottom plane (BT)

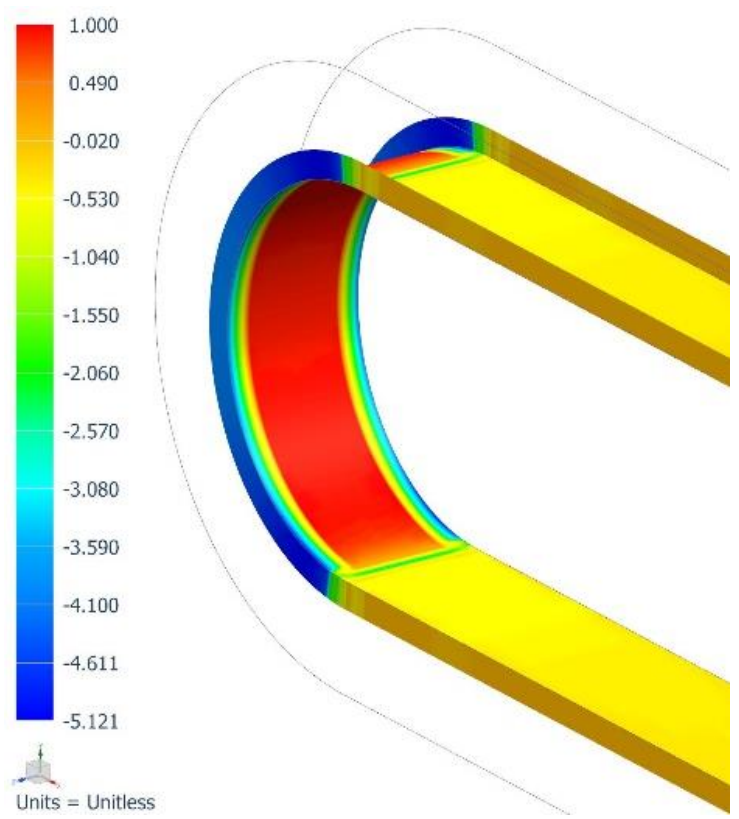

First ply - Middle plane (MID)

Fig. 8. Results of Hill's failure criterion in first (critical) ply of loop with four threads of fibres.

The results of the Hoffman's failure criterion are given in Fig. 9. The critical area of the failure was found on the contact cylindrical face of the loop approximately at an angle $60^{\circ} \pm 5^{\circ}$ relative to the longitudinal plane of the loop. Compliance with deviation up to $9 \%$ was determined in comparison with the experimental tests results (up to $9 \%$ for beginning of failure and up to $3 \%$ for full failure of the loop). 


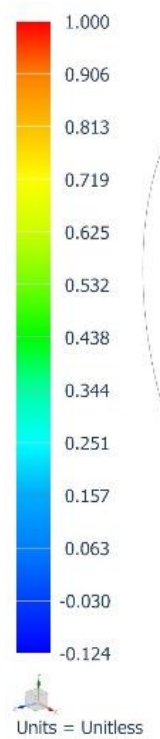

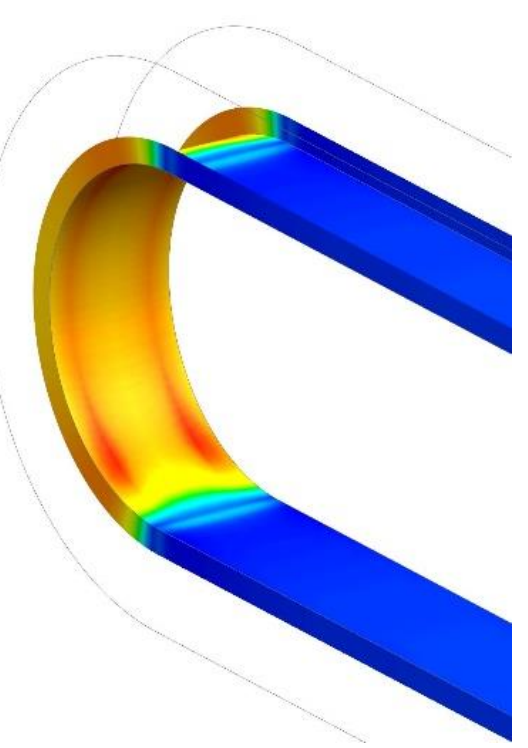

First ply - Bottom plane (BT)
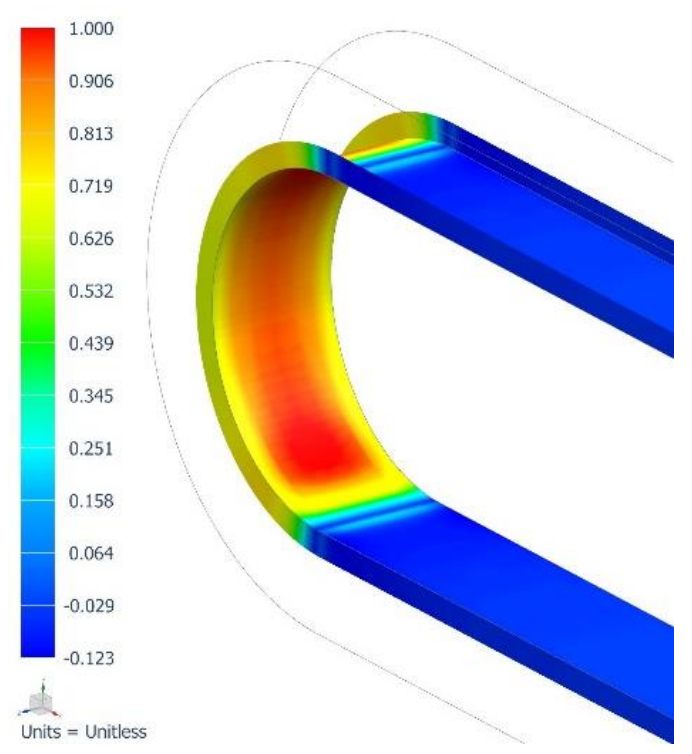

First ply - Middle plane (MID)

Fig. 9. Results of Hoffman's failure criterion in first (critical) ply of loop with four threads of fibres.

The results of the Tsai-Wu failure criterion are given in Fig. 10. The critical area of the failure was found on the contact cylindrical face of the loop approximately at an angle $55^{\circ} \pm 5^{\circ}$ relative to the longitudinal plane of the loop. The results most similar to the experimental test were obtained using this failure criterion. Compliance with deviation up to $7 \%$ was determined in comparison with the experimental tests results (up to $5.5 \%$ for beginning of failure and up to $7 \%$ for full failure of the loop).
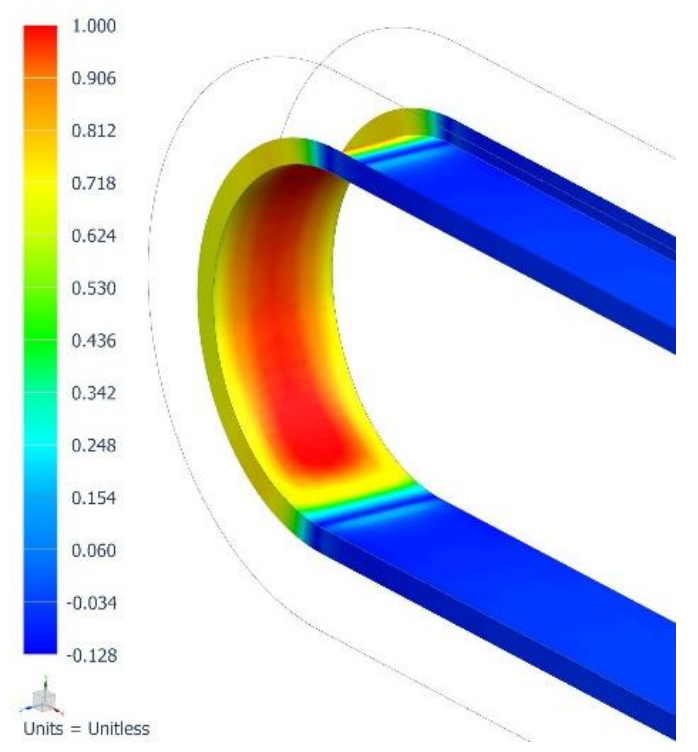

First ply - Bottom plane (BT)
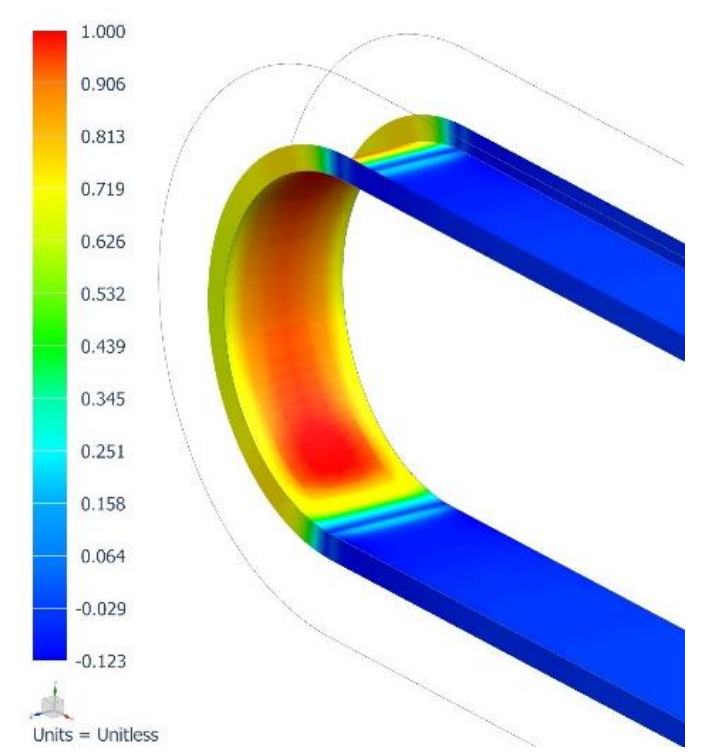

First ply - Middle plane (MID)

Fig. 10. Results of Tsai-Wu failure criterion in first (critical) ply of loop with four threads of fibres.

\section{Discussion}

In Fig. 11, the comparison of the results of the numerical simulation of the experimental tests for loops with four and seven threads of fibres can be seen. The $60 \%$ volume fraction of the fibres was used for the numerical simulation (that corresponds to the thickness of the loop $\mathrm{Q}=2.3 \mathrm{~mm}$ for four threads of fibres and thickness of the loop $\mathrm{Q}=3.5 \mathrm{~mm}$ for seven threads of fibres). The results show that the total strength of the wrapping loops increases with the thickness of the loop, but the strength of the matrix decreases. From a comparison of these results it was determined that the Tsai-Wu failure criterion has the closest compliance. 


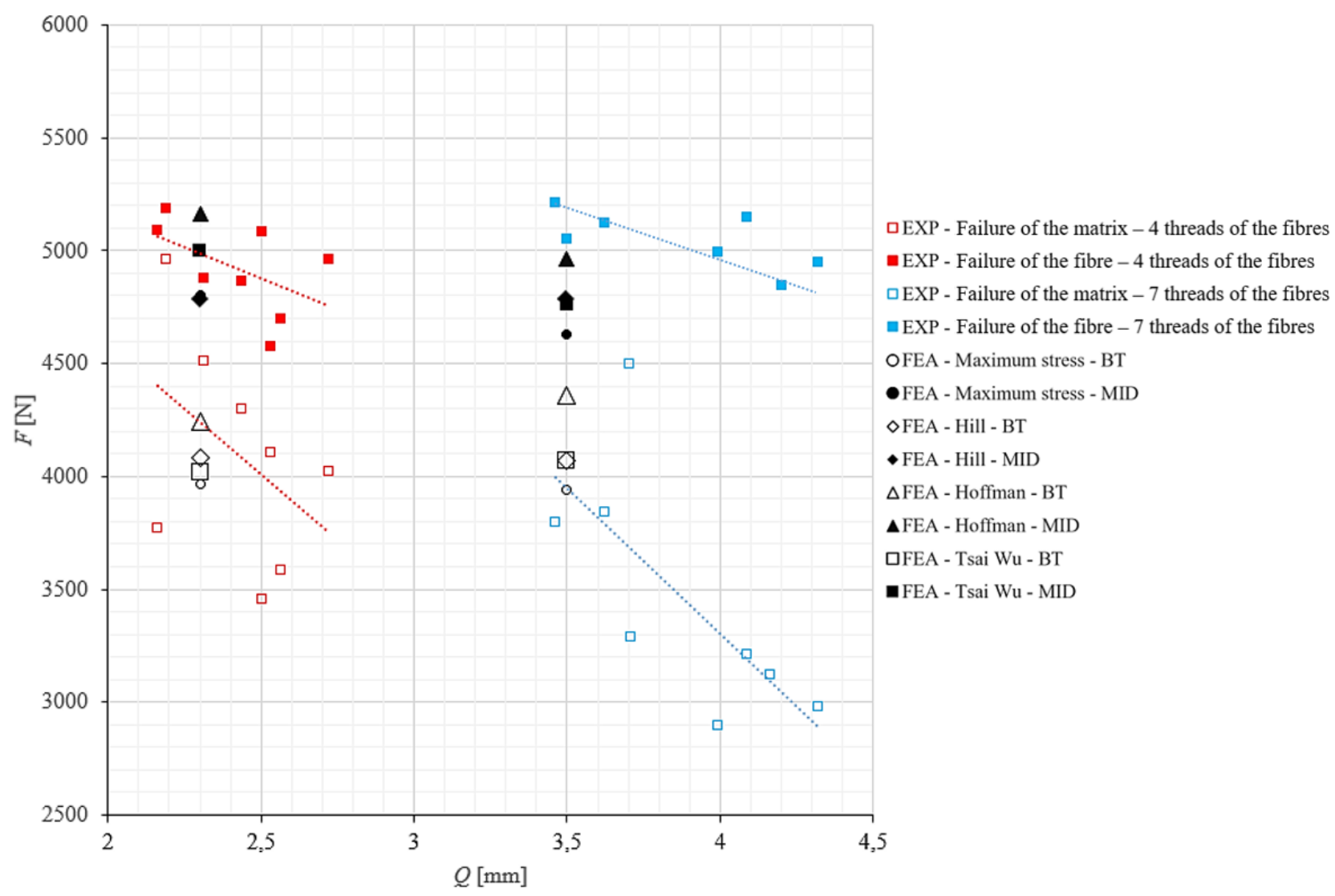

Fig. 11. Comparison of the results of the numerical simulations and experimental tests.

\section{Conclusion}

This paper deals with the determination of the strength of integrated high performance joints using ply-based numerical simulation. Simplified specimens (wrapping loops) made from unidirectional E-Glass roving were chosen for validation of the numerical simulation. Experimental tensile tests were done on sixteen specimens with two types of geometry. A ply-based FEM model of the loop was created. This type of FEM model allows the stress in individual plies of the laminate and their main planes to be evaluated separately (but suitability of used geometry is requirement/limitation of ply-based FEM method).

Four failure criteria for composite materials were used for determination of the strength of the wrapping loops. The failure in the middle plane in the most critical ply (first inner ply) was used for evaluating the strength of the loops. When comparing the numerical simulations and experimental tests, compliance with deviation up to $11 \%$ was found. The most accurate results (max. deviation up to 7\%) were obtained using the Tsai-Wu failure criteria. This research will continue by testing other materials (carbon fibres) and using direct mode failure criteria.

\section{Acknowledgments}

This contribution has been prepared under the project LO1502 'Development of the Regional Technological Institute' under the auspices of the National Sustainability Programme I of the Ministry of Education of the Czech Republic aimed at supporting research, experimental development and innovation.

\section{References}

[1] J. Krystek and R. Kottner. (2015). Load capacity prediction of carbon or glass fibre reinforced plastic part of wrapped pin joint. Materiali in Tehnologije, vol. roč. 49, pp. 957-960.

[2] R. Kottner, J. Krystek, R. Zemcik, J. Lombersky, and R. Hynek. (2014). Strength Analysis of Carbon Fiberreinforced Plastic Coupling for Tensile and Compressive Loading Transmission', in 52nd AIAA/ASME/ASCE/AHS/ASC Structures, Structural Dynamics and Materials Conference, American Institute of Aeronautics and Astronautics.

[3] C. A. Coulomb, 'In memories de mathematique et de physique. (1773). Academie Royal des Sciences par divers sans, vol. 7, pp. 343-382. 
[4] O. Mohr, 'Welche Umstände bedingen die Elastizitätsgrenze und den Bruch eines Materials. (1900). Zeitschrift des Vereins Deutscher Ingenieure, vol. 46, no. 1524-1530, pp. 1572-1577.

[5] V. Laš, Mechanika kompozitních materiálu. (2008). Pilsen. University of West Bohemia

[6] A. C. Long, Ed., Design and Manufacture of Textile Composites. (2005). 1 edition. Boca Raton, Fla.: Woodhead Publishing.

[7] R. C. Burk. (1983). Standard Failure Criteria Needed for Advanced Composites, AIAA, no. Vol. 21, p. Sv. pp. 5862.

[8] V. Valery V. and E. Morozov V. (2013). Advanced Mechanics of Composite Materials and Structural elements, 3rd Edition., Oxford: Elsevier.

[9] T. Ramesh and S. Chandra V. (2012). Damage and Failure of Composite Materials. Cambridge: Cambridge University Press.

[10] E. J. Barbero. (2010). Introduction to Composite Materials Design, Second Edition, 2 edition. Boca Raton: CRC Press.

[11] R. Hill. (1998). The Mathematical Theory of Plasticity, New York.

[12] R. Narayanaswami and H. M. Adelman. (1997). Evaluation of the Tensor Polynomial and Hoffman Strength Theories for Composite Materials, Journal of Composite materials, no. Vol. 11, pp. 366-377.

[13] I. I. Gol'denblat and V. A. Kopnov. (1965). Strength of glass-reinforced plastics in the complex stress state', Polymer Mechanics, vol. 1, no. 2, pp. 54-59.

[14] W. Van Paepegem and J. Degrieck. (2003). Calculation of damage-dependent directional failure indices from the Tsai-Wu static failure criterion', Composites Science and Technology, vol. 63, no. 2, pp. 305-310.

[15] S. W. Tsai and E. M. Wu. (1972). A General theory of strength for anisotropic materials', in Technical Report, Ohio.

[16] W. C. Cui, M. R. Wisnom, and M. Jones. (1992). A Comparison of Failure Criteria to Predict Delamination of Unidirectional Glass/Epoxy Specimens Waisted Through the Thickness', Composites, no. Vol. 23, pp. 158-166. 